\title{
Misinformation, subjectivism, and the rational criticizability of desire
}

\author{
Jay $\operatorname{Jian}^{1}$ (10
}

Published online: 14 May 2020

(C) The Author(s) 2020

\begin{abstract}
Orthodox Humeans about normative reasons for action believe that there are no rational principles governing the substantive content of desire. But they also believe that desires with misinformed content should be rejected and cannot be the proper subjective sources of normative reasons for action. These two ideas, I argue, in fact stand in tension with each other: The Humean rejection of misinformed desire actually has to invoke a feasibility principle for desire, a semi-substantive rational principle that is already built into the very conceptions of rationality and desire that underlie orthodox Humeanism. This rational principle then provides a new account of the substantive rationality of desire, which in turn has some interesting implications in metaethics and first-order normative theories.
\end{abstract}

Keywords Subjectivism · Humeanism - Idealization · Reasons for action · Desire · Normativity · Rationality

\section{Introduction}

According to subjectivism about practical normativity, what actions we have normative reason to do and what things are good for us are determined by our desires, in particular, by the desires that we would have when we are rational. On this view, facts about normative reasons for action and values are grounded in facts about what we would rationally desire. Some subjectivists believe that there are substantive or semi-substantive rational principles that prescribe or forbid desires with certain types of content. Indeed, the enterprise of Kantian and Neo-Humean subjectivism is to show how, given rational principles such as the Categorical

Jay Jian

jay.s.jian@gmail.com

1 Balliol College, University of Oxford, Oxford OX1 3BJ, United Kingdom 
Imperative (Korsgaard 1996: ch.3, 2009: ch.3) or the principle of not undermining our own agency and that in other people (Smith 2015), we wouldn't rationally desire to commit immoral acts. Substantive principles hence help Kantians and NeoHumeans to exclude desires with immoral content from being the eligible subjective sources of normativity. Other subjectivists, however, believe that there are no substantive rational principles for desire. On their view, our desires are only governed by the instrumental and formal coherence principles codified in contemporary decision theory, which merely govern their effective realization and coherence relation. It is this instrumentalist picture of rationality that provides the foundation for orthodox Humean subjectivism, which imposes very few constraints on what we would rationally desire, and hence on what desires can be the eligible subjective sources of normativity.

Orthodox Humean subjectivism (henceforth: orthodox Humeanism) presents the most thoroughly reductivist view about practical normativity. For, on this view, it is our desires that ultimately determine what actions we should perform and what objects we should acquire. Even if there are rational principles telling us that we should form a particular instrumental desire or that we should not hold a desire whose realization is incompatible with that of another, the "should" here is still generated by one of our desires. Desires are hence the ultimate sources of normativity unconstrained by further rational or normative principles. Orthodox Humeanism is thoroughly reductive in this way because of its commitment to the instrumentalist picture of rationality and the content uncriticizability of desire: our rational criticism of desire can never be made against a desire's substantive content; rather, it can only be made on the grounds of instrumental irrationality or internal incoherence.

Misinformed desire based on false beliefs or ignorance, however, presents a major exception to the Humean tenet of content uncriticizability. It is widely agreed among subjectivists-Humeans included-that misinformed desires should be excluded from the eligible subjective sources of normativity. Otherwise the resulting subjectivist accounts would be highly unintuitive and extensionally inadequate. If you desire to fetch a glass of transparent liquid in front of you only because you falsely believe it to be gin (when it is actually petrol), then surely your misinformed desire cannot ground a normative reason for you to fetch it (Brandt 1979: 13; Railton 1986a: 11, b: 173; Sobel: 1994, 2009; Smith 1994: 151-156; Williams 1982: 103-104, 1995: 36). ${ }^{1}$ However, the rejection of misinformed desires is precisely targeted at their content, for being misinformed is actually a content property. This then raises the suspicion that Humeans might have to engage in the content criticism of desire willy-nilly with their rejection of misinformed desires. In fact, quite a few normative realists have recently called this crucial Humean move into question. As they contend, the rejection of misinformed desires can make good sense only if we presuppose that there are some mind-independent reason-giving

\footnotetext{
1 There are a few philosophers who don't follow this subjectivist trend of rejecting misinformed desire. Heathwood (2005) and Lin (2019), for instance, have argued that all actual desires, even including misinformed ones, are valid subjective sources of normativity. It is just that misinformed desires can often be outweighed because they are more likely to frustrate other actual desires that we also have.
} 
features that the content of misinformed desires fails to properly respond to. The content of your misinformed desire to fetch the glass of liquid in front of you, for instance, presumably fails to respond to one crucial reason-giving feature, i.e. the liquid's being toxic. But if Humeans don't presuppose mind-independent reasongiving features like this, then it would be hard to see why they have a good rationale to reject your desire on the basis of its misinformed content.

I think the Humean rejection of misinformed desire is indeed targeted at its substantive content. Yet what this kind of criticism presupposes are not mindindependent normative facts about reason and the relevant reason-giving features. Rather, what it presupposes is a substantive rational principle for desire that is, surprisingly, already built into the very foundations of orthodox Humeanism. So orthodox Humeanism is actually not entirely content-neutral when it comes to the rationality of desire. In this paper I will argue for this seemingly contentious view and develop a new account of the rationality of desire accordingly.

According to the feasibility account that I shall develop, misinformed desire is problematic mainly because its misinformed content renders it infeasible. For example, some European explorers in the late 16th century desired that they discover the golden kingdom of El Dorado in South America. Their desire was misinformed because its content contained a representational element that purported to be true of something but failed to be true of any (i.e. the golden kingdom in South America). Given this, there was simply no existing object that corresponded to this misinformed representational element, and, a fortiori, no existing object that could constitute the realization thereof. So their desire that they discover the golden kingdom in South America was simply infeasible due to their misinformation. Such infeasibility in turn rendered their misinformed desire unfulfillable-when they embarked on their journey of fulfilling their desire for finding the golden kingdom, they were only engaging in a futile attempt that was bound to fail. But such a destined failure in desire fulfillment actually constitutes a defect in light of both the instrumentalist picture of rationality and the internal, constitutive aim of desire. That is why Humeans can justifiably divest the European explorers' misinformed desire of its reason-giving power.

This feasibility account, as I shall contend, offers a rationale for rejecting misinformed desires that is more helpful than the existing ones proposed in the literature, especially for subjectivists who aim to ground normativity in our motivating or volitional states. It will also reveal how there are actually two very different kinds of subjectivist accounts of normativity, i.e. motivation-based and liking-based subjectivism, which respectively ground normativity in our agential and receptive capacities. More importantly, it will show how the very conceptions of practical rationality and desire that underwrite orthodox Humeanism already implicate a rational feasibility principle, a semi-substantive rational principle that forbids desires with infeasible content. So it turns out that Humeans, given their own theoretical commitments, do have to go semi-substantive in the rational criticism of desire.

In Sect. 2 I briefly examine the existing accounts for the problem of misinformed desire and expose their limitations by distinguishing between two kinds of subjectivism. I propose the alternative feasibility account in Sect. 3 and explain why 
our desire and intention are subject to the rational feasibility principle in Sect. 4. Section 5 concludes by highlighting the significance of the feasibility principle.

\section{Misinformation and two kinds of subjectivism}

\subsection{The rationales for rejecting misinformed desire}

Misinformed desire comes in two types. We can have a misinformed telic desire for something $\mathrm{X}$ as an end in itself because of our ignorance or false beliefs about X's relevant properties. ${ }^{2}$ Or we can have a misinformed instrumental desire for something $\mathrm{X}$ as the means to another end $\mathrm{Y}$ because of our ignorance or false beliefs about the means-end relation between $\mathrm{X}$ and $\mathrm{Y}$. It is easier to come up with a Humean rationale for rejecting misinformed instrumental desire. After all, misinformed instrumental desire motivates us to devote our resources to the false measures that cannot in fact fulfill our telic desires. As such, it is problematic simply on the instrumentalist picture of rationality, upon which orthodox Humeanism rests.

It is more difficult, on the other hand, to come up with a Humean rationale for rejecting misinformed telic desire. In fact, this move is particularly vulnerable to the attack from realists. Parfit (2011: ch. 4), for instance, contends that it is inconsistent for Humeans to privilege informed desires based on true beliefs about the relevant features about an object (say, the toxicity of the liquid in the glass), yet to claim at the same time that these features do not provide any pre-existing normative reason for us to desire or not to desire it. Similarly, Enoch (2005) argues that desires formed under idealized epistemic conditions should be privileged mainly because the idealized conditions help them better track the relevant reason-giving features (Also see Lillehammer 2000 and Ripstein 2001: 37-55). Thus, according to these realists, the problem of misinformed telic desire lies in how misinformation prevents the desire from properly tracking features that provide pre-existing normative reasons to us. It is only in light of this realist picture that it makes good sense to reject and criticize misinformed telic desire. So the Humean rejection of misinformed telic desire, these realists complain, is only an ad-hoc move to save Humeanism from unintuitive consequences or extensional inadequacy. (For the sake of simplicity, in what follows "misinformed desire" will refer to misinformed telic desire alone, unless otherwise specified.)

There is, however, one natural Humean explanation for the problem of misinformed desire. As Sobel (2009) has recently argued, the rationale for the Humean rejection of misinformed telic desire is not that this kind of desire gets the relevant reason-giving features wrong, but that it gets the non-normative features of its object wrong. To illustrate, consider an example he offers: There are no preexisting normative facts concerning whether a certain ice cream flavor is good for you or whether you have a normative reason to have it. But a desire formed in light

\footnotetext{
${ }^{2}$ Telic desire is the desire for something as an end in itself. I borrow this term from Parfit, see his (2011: 44).
} 
of full information about its relevant features is indeed the very kind of desire that Humeans should privilege, for "only desires formed in light of an accurate understanding, phenomenological and otherwise, of what an option would be like are responsive to the true nature of the option under consideration (345)." Indeed, a misinformed desire for something X, Sobel argues, can only represent our favoring attitude toward the $\mathrm{X}$ as we conceive of it in light of our misinformation about it, but it doesn't really reflect a genuine favoring attitude on our part toward the $\mathrm{X}$ as it really is.

Railton (2012) has also proposed a similar argument. According to him, our desire constitutively involves a favorable affective attitude toward a representation of an object $X$ to be acquired (24-25). Such an affective attitude is sensitive to the feedback from our experiences when coming in touch with the real thing X (34-36). And the reason why our misinformed desire for something $\mathrm{X}$ is problematic, he contends, is that it is based on inadequate experiential feedback about the real thing $\mathrm{X}$-which can turn out to be something that we do not really enjoy or find rewarding.

Thus, according to Sobel and Railton, the problem of misinformed desire rather lies in how it fails to reflect our genuine favoring attitude toward the real thing due to our misinformation about it, or our lack of experience thereof. This genuineness account then provides a sensible Humean rationale for rejecting misinformed desire. After all, this kind of desire simply fails to reflect our genuine favoring attitude for an object as-it-really-is. But if we lack such a favoring attitude toward it in the first place, then for sure it won't be something that is good for us on orthodox Humeanism. Presumably we also won't have a normative reason to get it. That is why Humeans can legitimately reject your misinformed desire for the liquid in the glass without presupposing normative realism. For this desire simply fails to reflect what you genuinely want.

\subsection{Two kinds of subjectivism}

But further reflection reveals the limitation of the genuineness account. This is because there are two ways to understand the favoring attitude that is supposed to be the subjectivist ground for normativity, which give rise to two kinds of subjectivist accounts of normativity:

1. Motivation-based subjectivism: Desire is the source of normativity in virtue of how it typically reflects our motivation to realize a prospective object or a prospective state of affairs that we see under a favorable light.

2. Liking-based subjectivism: Desire is the source of normativity in virtue of how it typically reflects our liking for an actual object as-it-is, or for a prospective object or state of affairs as it-will-in-fact-be when it is realized.

To fix ideas, we can say having motivation consists in having a favoring attitude toward the realization of a prospective object or a state of affairs that we have in mind and want to bring about. Having a liking for something, on the other hand, consists in being disposed to enjoy the experiences that it brings and find them 
pleasurable or positive. ${ }^{3}$ For instance, I can see under a favorable light the prospective state of affairs that I become a successful lawyer, commit myself to it, and want to bring it about. But it might turn out that I won't really enjoy the experiences involved in legal career. In this case, I have the motivation toward becoming a successful lawyer but not the liking for it.

The genuineness account is well-suited to help liking-based subjectivism: Only if you are fully informed of the features of an actual object as-it-really-is [e.g. what a particular ice-cream flavor is really like (see Sobel 2009: 343-344)] or the features of a prospective object or state of affairs as it-will-in-fact-be [e.g. what it will be really like if you become a top athlete (see Railton 2012: 39-4)] can you be sure that you will have a genuine liking for it in the end. A misinformed desire presumably fails to reflect this kind of genuine liking for the actual thing or state of affairs that you will get. That is why this kind of desire cannot be the proper subjective source of normativity on liking-based subjectivism. In fact, both Railton and Sobel have stressed that an informed desire for an object $X$ has to be based on adequate phenomenological or experiential information about what it will be really like for us to have $\mathrm{X} .{ }^{4}$ And the examples that they appeal to all involve an agent with a misinformed desire for something that she won't really like or enjoy in the end. So the version of subjectivism that they had in mind and that their accounts are supposed to help, I presume, is one that is more akin to liking-based subjectivism.

The genuineness account is less helpful, however, for motivation-based subjectivism. Suppose you have in mind a mental representation of a prospective state of affairs (say, that you fetch a glass of gin in front of you) and you desire to bring it about as an end in itself. But suppose this mental representation is actually

\footnotetext{
3 This characterization of motivation has been accepted by most contemporary philosophers in one way or another. On this conception, to have motivation is to have an intentional state with world-to-mind direction of fit, to see its content under a favorable light (which contains a representation of a prospective state of affairs to be realized), and to be disposed to bring it about (see Smith 1987).

The notion of liking, on the other hand, has only started to receive more attention from philosophers in recent years. So it has a less established usage in philosophy. The notion of liking was introduced by psychologist Kent Berridge to contrast with that of wanting: to have a liking for something is to be disposed to feel pleasurable experiences (or experiences that one takes to be positive) from it, while to want something is to have the behavioral and motivational disposition of getting it, and these two states are importantly realized in distinct brain systems (see Berridge 1996: 4; Berridge and Kringelbach 2008: 458). Richard Holton (2009: ch.5) and Railton (2012) have largely adopted this understanding of liking. Although Parfit (2011: ch.6) depicts likings as states that render certain types of experiences pleasant or painful for us, his central idea is still that liking is a disposition to find pleasurable or positive a certain type of object. It is just that for Parfit the primary object of liking is experience rather than an external object.

4 Sobel contends that "idealization is an attempt to get those facts clearly and accurately into view...It is important for my purposes that the notion of facts here includes an accurate phenomenological impression of what an option would be like for one (2009: 344)". Railton also explicitly claims that one's informed desire for a particular kind of life needs to be based on full experience about what it is really like to lead that kind of life (2012: 40). This stress on phenomenological information can also be seen in their earlier work. In his earlier paper, Sobel (1994) distinguishes between the report and the experiential model of full information. And he contends that the latter kind of information is indispensable if one's informed desire is to determine what is good for one. Railton's suggestion that the full information must be vivid (1986a: 21-22, 30-31) also indicates that he understands full information primarily as a kind of phenomenological information.
} 
based on a misrepresentational element - the liquid in the glass that you take to be gin is actually petrol. Now, despite your misinformation about the liquid as-itreally-is, you still genuinely want it to be true that you fetch a glass of gin. You still see this prospective state of affairs in an attractive light and commit yourself to its realization. So why can't this attitude give you a normative reason to make it the case that you fetch a glass of gin in front of you, in line with the spirit of motivationbased subjectivism?

More generally, the standard objects of our likings are things-as-they-really-are. That is why our genuine likings can only be reflected by desires formed under full information about the objective features of actual things. The same point, however, is more controversial when it comes to our motivating states. Indeed, according to the motivating conception of desire, the standard object of our motivating state is a mental representation of a prospective state of affairs that we see under a favorable light and want to realize (Smith 1987). So despite our misinformation about the actual things, our misinformed desire qua a motivating state still constitutively involves a genuine favoring attitude toward the realization of a prospective state of affairs that we have in mind. ${ }^{5}$ And on motivation-based subjectivism, it is precisely this kind of favoring attitude that is supposed to give us a normative reason to realize it (for the sake of simplicity, in what follows I will call this kind of attitude favoring attitude toward the prospective).

I am not saying that our mere motivation to bring about a prospective state of affairs can alone generate normative reasons for action. For sure mere wanting or behavioral tendency to realize a prospective state of affairs is not enough. We also need to have a favoring attitude toward the prospective. I have to leave open what kind of favoring attitude toward the prospective can ground normative reasons for action on motivation-based subjectivism. Perhaps it is our valuing (Street 2012: 43-5), our commitment to the realization of a prospective state of affairs (Wallace 2004: 459-462), or our willing it to be reasoning-giving for us (Chang 2013: 92-97). Perhaps it also needs to be maximally influenced by rationality. Regardless, the spirit of motivation-based subjectivism lies in the recognition of the normative importance of our favoring attitude toward the prospective. ${ }^{6}$ Yet our misinformation about the actual things doesn't seem to impinge on the genuineness of this kind of attitude. So the genuineness account doesn't really explain why our misinformed desire qua a motivating state fails to reflect a genuine favoring attitude on our part, and why it should consequently lack reason-giving power on motivation-based subjectivism.

Of course, you might object that we still need full information about what the prospective thing that we desire will be really like when realized. Even if your misinformed telic desire involves your favoring attitude for getting a glass of gin in

\footnotetext{
5 This point has been recognized by both Sobel (2009: 347) and Dorsey (2017: 208).

${ }^{6}$ It is important for my purpose that this kind of favoring attitude toward the prospective is not just a kind expected liking. That is, it is not just a prediction about how we will like the prospective state of affairs in question once it is brought about. Otherwise this will bring us back to liking-based subjectivism and the genuineness account. Indeed, the central idea behind this account, we can say, is that our misinformed desire for something $\mathrm{X}$ is problematic primarily due to our false prediction about how we will like $\mathrm{X}$.
} 
front of you, it might still turn out that this is not what you really like-perhaps you won't enjoy the taste of gin anyway. So, as you might think, only if we have full information about what a prospective state of affairs will be really like when realized can our favoring attitude for its realization be genuine in a strict sense and give us a normative reason to fulfill it. Indeed, as Dale Dorsey (2017) has recently suggested, one necessary condition for our genuinely valuing an object $\mathrm{X}$ is that we would still have a favoring attitude toward $\mathrm{X}$ when we have full information about the $\mathrm{X}$ as-it-really-is and consider the different ways that $\mathrm{X}$ might be. So any version of value-based subjectivism, he contends, should invoke valuings formed under full information and imaginative consideration, just because full information is a condition for genuine valuing. And you might think that the same rationale also applies to our favoring attitude toward the prospective.

However, is it a condition for having a genuine favoring attitude of this kind that we have full information about what the prospective thing will be really like? Should the reason-giving power of our favoring attitude toward the prospective be always conditioned on such full information on motivation-based subjectivism? We have some reason to doubt this. A pregnant woman might desire that she becomes a full-time mother in the future, sincerely believe that this is the best life option for her, and strongly commit herself to it. It might turn out that she won't enjoy or like the experiences involved because of her misinformation about what full-time motherhood is actually like. But she simply doesn't care. For her the force of her love and devotion is precisely embodied in her commitment to full-time motherhood, whatever its consequences will be. Can't her favoring attitude for the prospective state of affairs that she has in mind still mean something on motivation-based subjectivism and give her some normative reason to bring it about? More generally, people commit themselves to various projects that they take to be expressive of who they are. They make an inner vow to themselves, "This is what I am going to commit myself to, for better or worse." Can the mere fact that they won't enjoy or like it in the future completely nullify the reason-giving force of this kind of attitude toward the prospective on motivation-based subjectivism? The answer is no, unless we want to give total normative deference to our likings and passive propensities for enjoyment, and to unduly downplay the normative importance of the attitudes that we can actively form toward prospective things in the future. Indeed, as I will explain in the next section, orthodox Humeanismmy main target in this paper-is precisely founded on the recognition of the normative importance of our favoring attitude toward the prospective. (See Appendix for a more general discussion on motivation- and liking-based subjectivism).

More importantly, even if we concede that we can have a genuine favoring attitude for the prospective only if we have full information about what the prospective thing will be really like, the genuineness account is still not able to help motivation-based subjectivism. This is because, unlike our liking, our favoring attitude toward the prospective is actually subject to a distinctive problem of infeasibility. Consider again the European explorers' desire that they discover the golden kingdom of El Dorado. Their favoring attitude toward the prospective state of affairs they had in mind could be said to be genuine in a strict sense: They had 
full information about what its realization would be like, and presumably they would have really liked, enjoyed, and valued it when it was realized. It was what they genuinely wanted all along. Their misinformation indeed made their desire problematic. But the problem was not that their misinformed desire failed to reflect their genuine favoring attitude. Rather, the problem was that the favoring attitude that it involved was for something that simply didn't exist and couldn't be brought about in the first place. In order to explain why motivation-based subjectivists have a good rationale to reject this kind of misinformed desire, we have to move beyond the genuineness account and invoke an alternative feasibility account.

Indeed, the genuineness account explains how misinformation can prevent our desires from reflecting our genuine likings, and why these desires are objectionable for liking-based subjectivism. The feasibility account, on the other hand, shows how misinformation can prevent our favoring attitudes toward the prospective from being feasible, and why our misinformed desires qua motivating states are problematic for motivation-based subjectivism. Let me explain it.

\section{The feasibility account}

\subsection{Why is misinformed telic desire infeasible?}

Let us begin by first considering how a telic desire qua a motivating state can ever be misinformed in the first place. On the face of it, this kind of desire doesn't even seem to be susceptible to the problem of misinformation at all. After all, its content is a prospective state of affairs that is supposed to be realized or "made true" rather than being true of something in the first place. So it is a bit difficult to see how it can ever be misinformed. Your telic desire that you bake a chocolate cake from scratch, for instance, cannot strictly be misinformed because it only contains a mental blueprint of a cake that is supposed to be made true later instead of being true of an existing cake. ${ }^{7}$ But I think our telic desire as a motivating state can still be said to be misinformed if its content has some representational elements that purport to be true of something in the first place. For instance, your telic desire that you fetch a glass of gin that is in front of you as an end in itself presumably includes a representational element that purports to be true of an object out there, i.e. the liquid in the glass in front of you. It is in virtue of the failure of a representational element like this that a telic desire as a motivating state can ever be misinformed.

What is then the problem with a misinformed telic desire whose content contains a representational element which fails to correctly represent things? Consider what motivation-based subjectivists should say about your misinformed telic desire that you fetch a glass of gin that is in front of you. One thing they should say is that in virtue of your favoring attitude toward the content element in your desire, there is a normative reason for you to realize it and make it the case that you fetch a glass of

\footnotetext{
7 Of course, this telic desire can be said to be misinformed if the chocolate cake turns out to be something that you don't genuinely like. But this will only bring us back to liking-based subjectivism.
} 
gin in front of you. However, there is another thing that motivation-based subjectivists should say. They should also say that since the content element in your desire contains a misrepresentation that fails to be true of any existing object, it is very unlikely to be made true. Your desired prospective state of affairs that you fetch a glass of gin in front of you is unlikely to be made true, for there is simply no glass of gin out there for you to get.

More generally, if the content of your telic desire involves a misrepresentational element, then it will be unrealistic - in both the sense of having no basis in reality and the sense of being infeasible: Its content involves a misrepresentation that purports to be true of an existing object but fails to be true of any (e.g. fetching $a$ glass of gin that is in front of you). As a result, its content can hardly be made true by an existing object that corresponds to the misrepresentational element and that constitutes the realization thereof (e.g. there is simply no object that corresponds to a glass of gin that is in front of you). Therefore, a misinformed telic desire like this is often infeasible and likely to lead to failures in your attempts to realize it. You will try to find out or think up the means to it, devote your limited and valuable resources to its fulfillment, but only to discover eventually that its content cannot really be made true. Thus, your misinformed telic desire qua motivating state turns out to be problematic in the same way as the European explorers' desire for the golden kingdom in South America. These desires all come out of touch with reality due to misinformation and consequently have realization conditions that can hardly be fulfilled. They in turn motivate us and set us out on a voyage that is highly likely to result in eventual failure.

Therefore, misinformation not only makes our telic desires unable to reflect our genuine likings for things-as-they-really-are. It also leads our telic desires qua motivating states to target at prospective states of affairs that are unrealistic and infeasible in the first place. It is the latter problem that poses a special threat for motivation-based subjectivists, who aim to ground normativity not in our likings, but in our favoring attitudes toward the prospective. That is why the genuineness account alone cannot help motivation-based subjectivism.

Notice I am only claiming here that misinformed telic desire is highly likely to result in failures in realization. This is because sometimes the misrepresentational elements involved in its content might still be accidentally true of something. For instance, if there is, unbeknownst to you, another glass of gin in front of you along with the petrol, then your misinformed desire might still be feasible in the end. I suppose a lot depends on the fine-grainedness of the content of telic desire in question and what it purports to be true of in the first place. If your desire is that you fetch this very glass of gin that is in front of you, then your desire would be infeasible in the end (because this very glass of liquid in front of you is just petrol). But if you only desire that you fetch a glass of gin that is within your reach, then your desire wouldn't be infeasible (because there are both glasses of petrol and gin near you). And if what you really want is only that you fetch any glass of gin, then your desire would not even be misinformed in the first place (because it doesn't purport to be true of any stuff near you). Real life cases are more complicated. That 
is why I am only making the more qualified claim that misinformed telic desires are highly unlikely to be satisfied due to its misinformed content. ${ }^{8}$

\subsection{Why is infeasible desire rationally defective?}

But why is infeasibility a defect for our telic desire qua motivating state? Why is it able to deprive our misinformed telic desire of its reason-giving power on motivation-based subjectivism? To see this, consider the following passage from Hume:

['T]is only in two senses, that any affection can be call'd unreasonable. First, when a passion [...] is founded on the supposition of the existence of objects, which do not really exist. Secondly, when in exerting any passion in action, we chuse means insufficient for the design'd end (1739-40: Book II, Part III, Section III).

Of course, for Hume, the irrationality involved in these two cases is primarily a kind of theoretical irrationality. But if you think that the second case here also involves a kind of practical irrationality, or at least a kind of practical defect, then you would also have good reason to say the same thing about the first case. This is because both cases involve the failure in the satisfaction of our passions (if passions can be said to have satisfaction conditions). In fact, Hume's diagnosis of the two kinds of unreasonable passion here corresponds to the defects of misinformed telic and instrumental desire respectively. This actually helps us to see why infeasibility is a kind of rational defect.

Instrumental rationality, as I take it, is a rational executive capacity for fulfilling desires. ${ }^{9}$ Thus, on the instrumentalist picture of rationality, a failure in rationality is primarily a failure in desire realization. Misinformed instrumental desire leads us to take the measures that cannot in fact fulfill our telic desires, and that is why it is problematic in an instrumentalist sense. Misinformed telic desire, on the other hand, also moves us to take the means to realize it. It is just that we will eventually discover that its content cannot really be brought about because it is infeasiblethere is simply nothing that corresponds to the misrepresentational elements in its content and that constitutes the realization thereof. So both kinds of misinformed

\footnotetext{
${ }^{8}$ Can it be argued that our telic desires must be desires with coarse-grained content and for general kinds of things in the world (say, your telic desire in the gin/petrol case has to be a desire for gin in general rather than a desire for this very glass of gin), such that they cannot really be misinformed in the end? I do not think so. For one thing, our telic desire can often have fine-grained content and target at something specific as an end in itself. One can, for instance, have in mind an ideal wedding, with all the details thought through, and one can surely want to realize that detailed, fine-grained mental content as an end in itself. For another, even a telic desire with course-grained content has representational purport and can therefore be subject to the problem of misinformation. Your telic desire for gin would be misinformed, for instance, if gin were to become no longer existent in the world (because, say, a new plant disease devastated juniper berry harvests, the very kind of berry that is used to flavor gin). In fact, I think almost every desire is subject to the problem of misinformation, as long as it has any representational content at all.

9 I lack the space to defend this idea here. For some arguments in favor of this view, see my ("The Executive Dimension of Instrumental Rationality”, unpublished manuscript, University of Oxford, 2020).
} 
desire lead to failures in desire realization. They are therefore both rationally defective on the instrumentalist conception of rationality. It is just that in the case of misinformed instrumental desire, the failure pertains to taking the wrong means, whereas in the case of misinformed telic desire, the failure results from having an infeasible end in the first place. That is why the infeasibility of misinformed telic desire can be said to constitute a kind of rational defect. (I will explain in more detail in the next section how feasible a telic desire needs to be if it is not to be rationally defective.)

The same point can also be made by focusing on the motivating dimension of desire. According to the direction of fit analysis, belief qua a representational state aims at representing a state of affairs that obtains in the world, whereas desire qua a motivating state aims at realizing a prospective state of affairs. Given this, belief can be said to be constitutively governed by the aim of truth, while desire by the aim of efficacy. However, if a desire has as its content a prospective state of affairs that is infeasible and unlikely to be realized, then it would be problematic simply in light of its own constitutive aim of efficacy, just as a belief with false content is problematic in light of its own internal aim of truth. This also explains why the infeasibility of misinformed telic desire constitutes a kind of defect.

You might object that it is the world that is supposed to fit the content of desire on the direction of fit analysis. So even if a misinformed telic desire has an infeasible content that is unlikely to be realized, the problem, as you might think, doesn't really lie in its infeasibility, but in the world's not cooperating (by not containing an object that corresponds to its misrepresentational element).

This understanding of the direction of fit of desire, however, is a bit crude. The idea of "fit" in the direction of fit analysis has a built-in causal connotation. To say that belief aims to fit the world, strictly speaking, is to say that belief is an intentional state whose content causally tracks (at least in normal circumstances) states of affairs in the world and the evidence for their obtaining. Similarly, to say that desire aims to make the world fit it is to say that desire is an intentional state whose content causally influences (at least in normal circumstances) an agent's action and leads her to realize the prospective state of affairs contained in it. Indeed, it is only on this causal understanding of direction of fit that we can explain how desire can causally motivate and regulate an agent's action in a way that is sensitive to its content. So the internal aim of desire is not just the world's fitting its content. Rather, it is its own causal efficacy in changing the world to fit its content. That is why the infeasibility of misinformed telic desire can be a defect in light of its constitutive aim.

More generally, human beings and higher animals have a distinctive mental capacity to have prospective objects or states of affairs in mind, to form favoring attitudes toward them, and to set out to bring them about. On motivation-based subjectivism, it is such favoring attitudes toward the prospective, together with our agential capacity to bring about the prospective things that we favor, that ultimately gives rise to normative reasons for action for us. ${ }^{10}$ In fact, orthodox Humeanism is

\footnotetext{
10 Again, I have to leave it open here what kind of favoring attitude toward the perspective can ground normative reasons for action for us, which is the topic for another paper.
} 
precisely premised on this basic line of thought and attempts to ground normative reasons for action in our motivating attitudes and our instrumental capacity to fulfill them (see Williams 1982; Hublin 1999). ${ }^{11}$ However, as we have just seen, both the instrumentalist conception of rationality and the motivating conception of desire take efficacy or desire-realization as their internal, constitutive aim. And the infeasibility of our misinformed telic desire simply constitutes a defect in light of this aim. That is why the proponents of motivation-based subjectivism-orthodox Humeans in particular-have a good rationale to reject and criticize misinformed telic desire qua a motivating state.

In fact, on orthodox Humeanism, normative reasons for action are reasons pertaining to the realization of the prospective states of affairs that we favor. So for sure misinformed desires for unrealizable states affairs would lack reason-giving power on this view. Indeed, if these desires had reason-giving power, they would implausibly ground normative reasons that ask us to engage in futile attempts to realize the infeasible and to waste our general resources for desire-fulfillment. This again explains why Humeans should exclude misinformed and infeasible telic desires from the eligible subjective sources of normativity. This then completes my feasibility account for the problem of misinformed telic desire.

\section{The feasibility principle}

\subsection{A further rational principle for desire}

The feasibility account provides a good rationale for Humeans to reject misinformed telic desire qua a motivating state on the basis of its infeasibility. However, it also shows, surprisingly, that Humeans cannot remain completely content-neutral with the rational criticism of desire given their own theoretical commitments. Indeed, the very foundations of orthodox Humeanism (i.e. the motivating conception of desire and the instrumentalist conception of rationality) take effective desire-realization as their constitutive aim. This aim in turn imports a rational feasibility principle for our desire, according to which any telic desire that is not minimally feasible is rationally defective. ${ }^{12}$ It is in light of this principle, as we have seen, that it makes sense for Humeans to reject misinformed telic desire and to divest it of its reason-giving power. This very rational principle, however, is also a semi-substantive rational principle targeted at the content of telic desire. Although it doesn't require us to desire any particular end, it does forbid us from desiring a specific kind of end, i.e.

\footnotetext{
11 See Appendix for a discussion on why orthodox Humeanism is a version of motivation-based subjectivism, and why Humeans shouldn't just simply adopt liking-based subjectivism instead.

12 Nozick (1993: 144) similarly contends that a rational person is someone who "does not have desires that she knows are impossible to fulfill" (cf. Hublin 1991: 25; Wallace 2001: 20-21). My view here is different from Nozick's. This is because on his view, our desire is only subject to a subjective feasibility constraint: it is irrational to have a desire that we believe to be infeasible. My view here, on the other hand, is that our desire is subject to an objective feasibility constraint: it is rationally problematic to have a desire that is in fact infeasible. As I will argue shortly, the subjective feasibility constraint can be plausibly construed as being derived from the objective one.
} 
an infeasible end. This then shows that to reject desire with misinformed and infeasible content, Humeans do have to go semi-substantive with the rational criticism of desire.

The feasibility principle is intuitive because we do rationally criticize people's projects by whether they are realistic or feasible enough, regardless of our moral or evaluative judgments about them. We are willing to accept that what kinds of life projects people have normative reason to pursue are relativized to their own desires. But those that are simply infeasible (say, attempting to learn to run at light speed) will be regarded as irrational and foolish regardless of their moral or evaluative character.

The feasibility principle is most plausible when it comes to a type of desire that figures as the best potential subjective source of normative reasons for action, namely, desires with volitional character, which include intentions, decisions, commitments, volitions as its subspecies. For the ease of discussion, here I will take intention as a placeholder for desire with volitional character. Our intention or volitional state has a distinctive satisfaction condition: It is realized only when the intended state of affairs is brought about by the agent herself because of it. For instance, if you intend to paint your table white, then you can fulfill your intention only if you paint the table white by yourself because of that very intention. In contrast, other kinds of desires are realized just when the desired state of affairs is brought about - even if by sheer luck, by other agents, or through a deviant causal chain. ${ }^{13}$ This distinctive satisfaction condition suggests that intention or volitional state has a stronger built-in claim to its own efficacy in moving an agent to change the world in accordance with its content. This stronger claim to its own efficacy in turn explains why many philosophers take intentions or volitional states to be both the primary triggers of the instrumental requirement (Bratman 2009; Broome 2013; Brunero 2012; Korsgaard 1997; Schroeder 2009; Wallace 2001; Way 2010) and the best potential subjective sources of normative reasons for action (Chang 2009, 2013; Korsgaard 1996, 2009; Wallace 2004, 2012). However, an intention or volitional state that is not even minimally feasible will also be defective in light of its internal, constitutive claim to its own efficacy.

In fact, intention or volitional state has a distinctive executive function: It functions to lead us to act and eventually bring about the prospective state of affairs that we intend. That is why the typical justification for an intention is derived from the justification related to the fulfillment of the intended state of affairs. For instance, if we travel back in time and ask the European explorers to justify their intention, they would presumably tell us how good it would be if they actually found the El Dorado. The infeasibility of an intention, however, can simply undercut its typical justification. This then provides an additional explanation as to why

\footnotetext{
13 Some philosophers have even argued that the content of intention is self-referential. They think that intention has the distinctive satisfaction condition pointed out here because the content of one's intention to $\varphi$ is that one is going to $\varphi$ because of that very intention (see Setiya 2007: 664; Harman 1976: 441; Searle 1983: 85-87). My claim here, however, is only about the satisfaction condition of intention, not its content. For it's a lot more controversial whether an intention's content must refer to itself. See (Mele 1987) for an argument as to how the satisfaction condition and the content of intention can come apart.
} 
infeasibility presents a valid basis for us to rationally criticize people's intention as a kind of mental state with a distinctive executive function.

Indeed, the feasibility principle plausibly explains why there is a belief constraint on our intention. Given the constitutive aim and the executive function of intention, it does seem irrational for an agent to intend to bring about a state of affairs $\mathrm{S}$ while at the same time believing that the realization of $S$ is not even possible or feasible for her to bring about in the first place-for the precise point and justification for intending so just lies in the realization of S. That is why if an agent is to be rational in intending to bring about $S$, then she must not believe that the realization of $S$ is impossible or infeasible for her to bring about. ${ }^{14}$ This belief constraint, I think, is in fact a subjective, second-best rational requirement ${ }^{15}$ derived from the feasibility principle: Our intention formation should be rationally sensitive to our beliefs about infeasibility, for infeasibility in the first place constitutes a defect for our intention as a kind of intentional state that constitutively aims at its own efficacy.

Our discussion on intention suggests that Humeans are in fact faced with a general dilemma: The stronger claim that a type of intentional state has to its own efficacy, the more promising it would appear as a potential subjective source of reason for action. So compared to mere hopes, our desires or goal-states can more plausibly ground normative reasons for action for us. And compared to mere desires, our intentions or commitments seem to be even better subjective sources of reasons for action. But the stronger claim that a type of intentional state has to its own efficacy, the more likely it would be subject to the rational governance of the feasibility principle as its internal constitutive principle. So either Humeans have to settle for a less than satisfactory subjective source of normativity, or they have to incorporate the semi-substantive feasibility principle in their picture of rationality eventually.

\subsection{How feasible?}

How feasible must our desire or intention be if it is not to be deemed rationally defective? Does the feasibility principle entail that it would be more rational for us to hold desires or intentions that can be easily satisfied? I am inclined to say that the feasibility principle only functions as a negative rational constraint on our intention: An intention that is not even minimally feasible should be judged as rationally defective in light of its constitutive aim of efficacy. But once an intention satisfies the constraint of minimal feasibility, feasibility can no longer be a relevant consideration in our rational assessment of intention. How minimally feasible an intention must be is a question that I have to leave open here. Clearly an intention that is impossible to realize would be rationally defective. But other than that, I

\footnotetext{
${ }^{14}$ Here I go for a weaker reading of the belief constraint on intention. To be rational in intending to $\varphi$, what is needed is not our having a further belief that it is feasible or possible for us to $\varphi$. Rather, what is needed is our lacking the belief that it is infeasible or impossible for us to $\varphi$.

15 It is a second-best rational principle because, in order to follow the feasibility principle, the best that we can do is to just consult our beliefs about which states of affairs are infeasible or impossible for us to realize and to comply with the belief constraint.
} 
think we could only gauge the level of minimal feasibility that an intention should possess by considering concrete cases and constructing from them a more general theory of feasibility.

Of course, you might still think that an intention that is not even minimally feasible can still be rational in itself. A smart mathematician, for instance, might intend to find out a difficult proof for a complicated theorem, and her search for it might turn out to be not even minimally feasible. But such infeasibility, as you might think, doesn't really render her intention and attempt irrational.

I think we have this kind of intuition primarily because of two reasons. The first is that the infeasibility of an intention can sometimes be compensated by the enormous value involved in its potential fulfillment (say, the value in finding out the proof). The second reason is that many intentions that are not objectively feasible can still perfectly satisfy the subjective feasibility constraint. Our smart mathematician, for instance, might intend to find out the proof while lacking the belief that the search for it is simply infeasible. Indeed, if she has the explicit belief that it's simply impossible for her to find out the proof in the first place, then we certainly would have some difficulty in understanding the point and the rationality of her intention in doing so. ${ }^{16}$ Now given that many of us embrace a coherentist conception of rationality, we would indeed tend to withhold our rational criticism when it comes to infeasible intentions that satisfy the subjective feasibility constraint - after all, such intentions still stand in a coherent relation with one's beliefs about feasibility. However, if we take instrumental rationality to consist in our rational executive ability for fulfilling our intentions, then infeasible telic intentions, along with misinformed instrumental intentions, would indeed be rationally problematic in a non-coherentist sense. On the instrumentalist conception of rationality, failures of rationality are primarily failures in the exercise of our mental capacity for intention-fulfillment. Since infeasible telic intention and misinformed instrumental intention both lead to such failures, both of them can be seen as sources of instrumental irrationality.

Even if you want to insist that irrationality, including instrumental irrationality, must consist in the internal incoherence relation between our intentional states, ${ }^{17}$ an infeasible intention can still be said to exhibit a sort of internal tension. Indeed, if we focus on the constitutive functions of belief and intention, then we can see that false belief and infeasible intention both involve a kind of internal tension between the character of their content (i.e. falsity and infeasibility) and the very aim that they are supposed to achieve given their core functions (i.e. truth and efficacy). And this sort of tension can also be said to constitute a specific sort of function-based rational defect (though not an instance of strict irrationality, given that the idea of irrationality might simply carry too much of a coherentist connotation). It is on this

\footnotetext{
16 Of course, we can still regard her intention and attempt to do so as admirable, for many admirable things to do can be sometimes irrational.

17 For accounts that construe instrumental rationality as a kind of internal coherence in either our intentions or the beliefs entailed by our intentions, see (Bratman 2009; Broome 2013; Brunero 2012; Setiya 2007; Wallace 2001; Way 2010; Wedgwood 2011).
} 
broader, function-based conception of rationality, I think, that we can regard infeasible intention or desire as rationally defective.

In any case, recall that most subjectivists attempt to ground normativity in what we would rationally desire or intend. And in order for Humeans to exclude misinformed instrumental and telic desires from the eligible subjective sources of normativity, they have to say that both types of misinformed desires aren't among the desires that we would form when we are rational, even though these desires might still cohere well with our false beliefs. So at least Humeans-my main target in this paper-have to regard both misinformed instrumental desire and infeasible telic desire as rationally defective on their preferred instrumentalist picture of rationality. Still, if you think that objective infeasibility cannot constitute a rational defect, then I will be happy to concede that the infeasibility of our intention or desire only makes for a sort of normative defect in light of its constitutive aim of efficacy. The feasibility account still stands as a good Humean rationale for rejecting misinformed telic desire. And it still reveals that the very foundations of orthodox Humeanism already import a substantive normative (though not rational) principle for criticizing the content of our desire.

\subsection{How substantive is the feasibility principle?}

You might think that the feasibility principle is still quite content-neutral and formal. After all, this principle only sets a negative feasibility constraint on our intention. But it doesn't really tell us how certain kinds of intentions (say, the intentions to commit immoral acts) are irrational in themselves, apart from infeasible and foolish ones. So how could the feasibility principle have any substantive implications on first-order normative theories?

The defense of moral rationalism is beyond the scope of this paper. But I think the feasibility principle does have more substantive implications on first-order normative theories. First, this principle allows human nature to set meaningful constraints on what we can rationally intend. One source of infeasibility lies in the way things are, say, how there is no existing object that corresponds to the representational element in the content of our intention and that constitutes the realization thereof. It is this source of infeasibility that makes our misinformed telic intention rationally defective. But another important source of infeasibility lies in the limitation to our capacities as human beings. For instance, an intention to run at light speed is infeasible given our physical constraint, while an intention to calculate every logical consequence of our beliefs is infeasible due to our psychological constitution. So our limitations as human beings, together with the feasibility principle, can also determine whether an intention is rational and capable of being a legitimate source of normative reasons for action for us. Such rational constraints from the limits of our capacities in turn highlight the importance of self-knowledge to our practical rationality: To avoid infeasible (and hence irrational) intentions, it is not enough to have full information about the external world. A sober understanding of the limitations to our own capacities is also required.

Second, as our discussion on the limit to our capacities here suggests, the rational defect of infeasibility can actually be dealt with by either revising our infeasible 
intention or improving our capacities pertaining to its realization. So the feasibility principle also gives rise to derivative rational or normative requirements on us to enhance our capacities, and to rely on one another's agency through cooperation and reciprocity. And both types of requirements can potentially provide a rational justification for morality. Perhaps its justification can be derived from the rational requirement on how we should help with, and refrain from hindering, our own agency and that in other people (Smith 2015). Or perhaps its justification is instead derived from the rational requirements governing the cooperation among us as agents (Gauthier 1987).

In any case, regardless of the substantiveness of the feasibility principle itself, it's clear that few have noticed how this rational principle is already implicated in the theoretical commitments of orthodox Humeanism. And it's also clear that this principle can have substantive normative implications. So the feasibility principle only presents our first step toward an alternative account of the substantive rationality of desire. It should not be the final word.

\section{Conclusion}

We can draw four lessons from our discussion here. First, we can distinguish between liking-based and motivation-based subjectivism. Misinformation presents different threats to these two kinds of subjectivism, for it can either make our telic desire unable to reflect our genuine likings or lead it to aim at states of affairs that are unable to be realized.

Second, the very conceptions of practical rationality and desire that underlie the orthodox Humeanism (namely, the instrumentalist conception of rationality and the motivating conception of desire) already implicate a rational feasibility principle for desire. And Humeans have to invoke this principle in order to exclude misinformed and infeasible telic desires from the eligible subjective sources of normative reasons for action. In fact, even motivation-based subjectivists who don't follow the orthodox Humean program have to appeal to the infeasibility principle. This is because most of these non-Humean subjectivists still accept the instrumental principle and take our favoring attitudes for the prospective to be main subjective sources of normativity. (It's just that they think that there are substantive rational principles for desire in addition to the instrumental principle, and that our favoring attitude toward the prospective needs to involve something more (e.g. commitment, valuing, or taking something to be reason-giving) in order for it ground normative reasons for action.) So these non-Humean subjectivists also need to invoke the feasibility principle in order to exclude misinformed (and hence infeasible) favoring attitudes toward the prospective from grounding normative reasons for action.

Third, the feasibility principle applies most naturally to intention or volitional state. This is because intention has a stronger claim to its own efficacy in moving us to realize a prospective state of affairs. Indeed, the core function of intention is to lead us to act and to realize a prospective state of affairs because of it. So the point of, and the typical justification for, an intention lie in the realization of the prospective state of affairs intended. But infeasibility simply nullifies this very point 
and justification. That is why an intention that is not even minimally feasible is rationally criticizable. And Humeans are actually faced with a central problem: Presumably, the most promising subjective sources of normative reasons for action are intentional states with a stronger claim to their own efficacy. But the stronger claim that a type of intentional state has to its own efficacy, the more likely it would be subject to the rational governance of the feasibility principle.

Finally, the feasibility principle casts doubt on the Humean tenet of the content uncriticizability of desire and intention. As we have seen, in order to reject misinformed telic desire, Humeans need to appeal to the feasibility principle, which is grounded in the instrumentalist picture of rationality and the internal constitutive aim of desire. This principle, however, is actually a semi-substantive rational principle that forbids desires and intentions with a particular type of content, namely, infeasible content. And it in turn supports further rational principles for enhancing our agential capacity and for mutual cooperation. So it turns out Humeans cannot stay entirely content-neutral with the rational criticism of desire after all. The very foundations of orthodox Humeanism already import a semisubstantive rational principle for desire, and they actually invite us to move beyond mere instrumental and formal coherence principles.

Acknowledgements I am grateful to Alison Hills for her valuable feedback on multiple drafts of this paper. I am also thankful to Ruth Chang, Jonas Olson, Peter Railton, and Ralph Wedgwood for helpful discussions, Alexander Heape and Drew Johnson for detailed written comments, and an anonymous referee and the audiences at the University of Oxford, Stockholm University, and University of Connecticut for their helpful suggestions.

Open Access This article is licensed under a Creative Commons Attribution 4.0 International License, which permits use, sharing, adaptation, distribution and reproduction in any medium or format, as long as you give appropriate credit to the original author(s) and the source, provide a link to the Creative Commons licence, and indicate if changes were made. The images or other third party material in this article are included in the article's Creative Commons licence, unless indicated otherwise in a credit line to the material. If material is not included in the article's Creative Commons licence and your intended use is not permitted by statutory regulation or exceeds the permitted use, you will need to obtain permission directly from the copyright holder. To view a copy of this licence, visit http:// creativecommons.org/licenses/by/4.0/.

\section{Appendix: Motivation-based versus Liking-based Subjectivism}

You might wonder why Humeans shouldn't just be content with liking-based subjectivism and the genuineness account. After all, if Humeans choose to ground normativity in our likings for actual things as-they-really-are, then they just don't need to worry about the infeasibility problem that inflicts motivation-based subjectivism in the first place. So you might think that Humeans don't really have to invoke the feasibility account and the semi-substantive feasibility principle that I proposed in this paper. Let me address this concern very quickly here.

To begin, motivation-based subjectivism actually represents the orthodox Humean account about normative reasons for action. Most Humeans have tended to focus on the motivating dimension of desire (rather than liking) and take it to be 
the very feature in virtue of which desire is the source of normative reason for action. For instance, what Williams appeals to in his account of normative reason are precisely the states in our subjective motivational set $(1982,1995)$. And most of the states that he considers involve a prospective object to be realized. For instance, when he discusses whether our normative beliefs can give rise to motivating states, he mostly formulates the object of our motivating state in terms of a prospective action to be performed in the future (1982: 108-109). Another central type of state that he appeals to involves "projects, as they may be abstractly called, embodying commitments of the agent (105)." But the idea of project also involves a prospective mental plan to be carried out. Michael Smith likewise takes desires to be the sources of normative reasons for action, more specifically, the desires of our rational selves about what our actual selves should do (1994: ch. 5). But for him, desire is precisely a motivating state with a representation of a prospective state of affairs to be realized (ch. 4). He briefly considers whether normative reasons are relativized to our likings for different kinds of things, such as our likings for different kinds of drinks. But he argues in the end that such idiosyncratic tastes or likings can actually be conceived as the features of the circumstances that our actual selves are in, and our idealized selves might not take such features into consideration when they form desires concerning what our actual selves should do (170-171).

More importantly, there are actually independent reasons for Humeans (or subjectivists in general) to take motivation-based subjectivism seriously instead of completely deferring to our likings. First, liking-based subjectivism is in more danger of collapsing into a form of realism. Parfit and Scanlon, for instance, have both contended that normative reasons grounded in our likings are actually objective hedonic reasons grounded in facts about what kinds of things are enjoyable for us (Parfit 2011: 67; Scanlon 1998: 44-45). Parfit has even suggested that our likings admit of a more objectivized understanding, such that reasons grounded in them are more akin to objective rather than desire-based reasons (Parfit 2011: 52-56, 67). Of course, it's controversial whether our likings should be understood as subjective states, or whether they can be "objectified" into facts about our dispositions for feeling pleasures. ${ }^{18}$ But motivation-based subjectivism is at least less vulnerable to the potential problem of collapsing into realism, because at least most philosophers can agree that motivating states are paradigm instances of subjective states.

Second, I think the normativity involved in well-being or personal good is best captured by liking-based subjectivism, whereas that involved in normative reason for action is better accommodated by motivation-based subjectivism. Well-being involves a receptive kind of normativity - even beings without rational agency can be said to have things that contribute to their well-being or things that are good for them. And it seems that a thing can contribute to one's well-being primarily in virtue of how it possesses features that suit one's likings and is able to bring about the experiences that one enjoys. Indeed, the latter experiential aspect is particularly

\footnotetext{
18 Railton famously adopts this more objectivist understanding of psychological constitution and calls himself a realist, see (Railton 1986a: 25-26; 1986b: 173-176). For an argument concerning how this move of "objectifying the subjective" will still land one in a broadly subjectivist position, see Sobel (2012).
} 
important when it comes to well-being (Griffin 1986: 16-20). Normative reason for action, on the other hand, involves an active kind of normativity-only beings with agential capacity and capable of effectuating changes in the world can have reasons for action. And it seems that one has normative reasons for action in virtue of one's favoring attitudes toward the prospective and one's agential capacity for realizing the prospective things that one favors. I believe this is the central line of thought that informs the subjectivist program about normative reasons for action. But this program, in so far as it grounds normative reasons for action in one's agential capacity for realizing the prospective things that one desires, has to incorporate the feasibility principle as one of the core rational principles for desire. It has to move beyond mere instrumental and formal coherence principles.

\section{References}

Berridge, K. (1996). Food reward: Brain substrates of wanting and liking. Neuroscience and Biobehavioral Reviews, 20(1), 1-25.

Berridge, K., \& Kringelbach, M. (2008). Affective neuroscience of pleasure: Reward in humans and animals. Psychopharmacology (Berl), 199(3), 457-480.

Brandt, R. (1979). A theory of the good and the right. Oxford: Clarendon Press.

Bratman, M. (2009). Intention, belief, and instrumental rationality. In D. Sobel \& S. Wall (Eds.), Reasons for action (pp. 13-36). Cambridge: Cambridge University Press.

Broome, J. (2013). Rationality through reasoning. Chichester: Wiley.

Brunero, J. (2012). Instrumental rationality, symmetry and scope. Philosophical Studies, 157(1), $125-140$.

Chang, R. (2009). Voluntarist reasons and the sources of normativity. In D. Sobel \& S. Wall (Eds.), Reasons for action (pp. 243-271). Cambridge: Cambridge University Press.

Chang, R. (2013). Commitment, reasons, and the will. In R. Shafer-Landau (Ed.), Oxford studies in metaethics (Vol. 8, pp. 74-113). Oxford: Oxford University Press.

Dorsey, D. (2017). Idealization and the heart of subjectivism. Noûs, 51(1), 196-217.

Enoch, D. (2005). Why idealize? Ethics, 115(4), 759-787.

Gauthier, D. (1987). Morals by agreement. Oxford: Clarendon Press.

Griffin, J. (1986). Well-being: Its meaning, measurement and moral importance. Oxford: Oxford University Press.

Harman, G. (1976). Practical reasoning. Review of Metaphysics, 79, 431-463.

Heathwood, C. (2005). The problem of defective desires. Australasian Journal of Philosophy, 83(4), 487-504.

Holton, R. (2009). Willing, wanting, waiting. Oxford: Oxford University Press.

Hublin, D. (1991). Irrational desires. Philosophical Studies, 62(1), 23-44.

Hublin, D. (1999). What's special about humeanism. Nô̂s, 33(1), 30-45.

Hume, D. (1739-1740). A treatise of human nature, In L. A. Selby-Bigge (Ed.), 2nd ed. revised by P. H. Nidditch. Oxford: Clarendon Press, 1975.

Korsgaard, C. (1996). The sources of normativity. Cambridge: Cambridge University Press.

Korsgaard, C. (1997). The normativity of instrumental reason. In G. Cullity \& B. Gaut (Eds.), Ethics and practical reason (pp. 215-254). Oxford: Clarendon Press.

Korsgaard, C. (2009). Self-constitution: Action, identity, and integrity. Oxford: Oxford University Press.

Lillehammer, H. (2000). Revisionary dispositionalism and practical reason. Journal of Ethics, 4(3), 173-190.

Lin, E. (2019). Why subjectivists about welfare needn't idealize. Pacific Philosophical Quarterly, 100(1), $2-23$.

Mele, A. (1987). Are intentions self-referential? Philosophical Studies, 52(3), 309-329.

Nozick, R. (1993). The nature of rationality. Princeton, NJ: Princeton University Press.

Parfit, D. (2011). On what matters (Vol. 1). Oxford: Oxford University Press. 
Railton, P. (1986a). Facts and values. Philosophical Topics, 14(2), 5-31.

Railton, P. (1986b). Moral realism. Philosophical Review, 95(2), 163-207.

Railton, P. (2012). That obscure object, desire. Proceedings and Addresses of the American Philosophical Association, 86(2), 22-46.

Ripstein, A. (2001). Preferences. In R. Frey \& C. Morris (Eds.), Value, welfare, and morality (pp. 37-55). Cambridge: Cambridge University Press.

Scanlon, T. (1998). What we owe to each other. Cambridge, MA.: Belknap Press.

Schroeder, M. (2009). Means-end coherence, stringency, and subjective reasons. Philosophical Studies, 143(2), 223-248.

Searle, J. (1983). Intentionality. Cambridge: Cambridge University Press.

Setiya, K. (2007). Cognitivism about instrumental reason. Ethics, 117(4), 649-673.

Smith, M. (1987). The humean theory of motivation. Mind, 96(381), 36-61.

Smith, M. (1994). The moral problem. Oxford: Oxford University Press.

Smith, M. (2015). The magic of constitutivism. American Philosophical Quarterly, 52(2), 187-200.

Sobel, D. (1994). Full information accounts of well-being. Ethics, 104(4), 784-810.

Sobel, D. (2009). Subjectivism and idealization. Ethics, 119(2), 336-352.

Sobel, D. (2012). Parfit's case against subjectivism. In R. Shafer-Landau (Ed.), Oxford studies in metaethics (Vol. 6, pp. 52-78). Oxford: Oxford University Press.

Street, S. (2012). Coming to terms with contingency: Humean constructivism about practical reason. In J. Lenman \& Y. Shemmer (Eds.), Constructivism in practical philosophy (pp. 40-59). Oxford: Oxford University Press.

Wallace, J. (2001). Normativity, commitment, and instrumental reason. Philosophers' Imprint, 1(1), 1-26.

Wallace, J. (2004). Constructing normativity. Philosophical Topics, 32(1/2), 451-476.

Wallace, J. (2012). Constructivism about normativity: Some pitfalls. In J. Lenman \& Y. Shemmer (Eds.), Constructivism in practical philosophy (pp. 18-38). Oxford: Oxford University Press.

Way, J. (2010). Defending the wide-scope approach to instrumental reason. Philosophical Studies, 147(2), 213-233.

Wedgwood, R. (2011). Instrumental Rationality. In R. Shafer-Landau (Ed.), Oxford studies in metaethics (Vol. 6, pp. 280-309). Oxford: Oxford University Press.

Williams, B. (1982). Internal and external reason. In Moral luck (Cambridge: Cambridge University Press), pp. 101-103.

Williams, B. (1995). Internal reasons and the obscurity of blame. In Making sense of humanity (Cambridge: Cambridge University Press), pp. 35-45.

Publisher's Note Springer Nature remains neutral with regard to jurisdictional claims in published maps and institutional affiliations. 